\title{
End stage kidney disease in the elderly: Hope for the best
}

\author{
Patrícia Valério, Ana Farinha \\ Nephrology Department, Centro Hospitalar de Setúbal
}

\section{ABSTRACT}

With an increased number of aged chronic kidney disease (CKD) patients, along with medical and technological advances, the options to approach end-stage kidney disease (ESKD) have multiplied. Nephrologists should be aware that taking care of elderly patients is different from taking care of younger ones. The spectrum of choices is as wide as the functional status of these patients. For fit ones, the main goal should be to restore function as much as possible and to rehabilitate. On the other hand, for frail patients, the expectations should be realistic in terms of survival, disease trajectory and symptomatic control, because while kidney replacement therapies can prolong life, they do not cure. The issue is complex due to its multidimensional perspective, so decisions must take into account the patient's options, respecting his/her autonomy, dignity and quality of life.

This text aims to review the particularities of geriatric CKD patients' assessment towards options to care for ESKD, in a specific population which is growing in our practice.

Keywords: Conservative care, end stage kidney disease, geriatric assessment, kidney replacement therapy

\section{INTRODUCTION}

In the same way that taking care of children has become a differentiated specialty, taking care of the elderly differs from caring for young adults. Aging is not a uniform process and is much more complex than childhood. Any nephrology appointment reflects the great diversity of the aging pattern: some patients remain fit and independent while others are frail, even when they present with the same chronological age. The different presentations are not solely a result of accumulated comorbidities, because even in their absence, we can recognize geriatric syndromes that compromise a healthy aging. Furthermore, the same pathology may progress in different ways, with different manifestations, different sequels, and thus with very different losses of physiological reserve. In this scenario, even for a disease that we are familiar with, end-stage kidney disease (ESKD), choosing the right treatment option is all but simple.

\section{PATIENT-CENTERED APPROACH AND SHARED DECISIONS}

In daily practice, nephrologists are trained to deal with chronic kidney disease (CKD), its complications and treatment options. In recent years, this routine has become more challenging as patients are older and their pathologies more complex.

Dialysis has become established as the main therapy for CKD. However, the paradigms learned with that experience do not always suit these patients who are becoming the rule, not the exception. They present a diversity of trajectories that highlight the need to turn from a disease-centered approach to a patient-centered one.
To adequately manage an old CKD patient, two key questions should be in our mind. The first is "Is this patient really reaching the need for kidney replacement therapies (KRT)?". For the elderly, discussions regarding KRT should be based on the rate of progression of CKD, but they should also take into account the competitive risk of dying from other comorbidities. ${ }^{1}$ This has led European Renal Best Practice to build a guideline on the management of older patients with CKD. ${ }^{2}$

Some models have been studied to predict progression of CKD in the elderly, along with mortality or functional loss. ${ }^{2}$ The ERA-EDTA proposes the use of Kidney Failure Risk Equation (KRFE) score $^{3}$ to evaluate the risk of progression CKD, and the Bansal score ${ }^{4}$ to evaluate the competitive risk of mortality. Even if these tools are not widely widespread and validated, those points must be taken into account to avoid stressful conversations with patients or waste of resources for facilities (Figure 1). ${ }^{2}$

The second question, as challenging as the first one, is "What KRT choice is the best one for this specific patient?" When ESKD is a probable outcome, two principles must not be forgotten: patients have the right to be involved in decision-making and options should not be excluded or precluded based only on chronological age.

To make decisions, two conditions must be satisfied: proper communication and autonomy. The first demands knowledge of clinical context, namely prognosis (including risk of hospitalization, life expectancy, and quality-of-life expectations with and without treatment). ${ }^{5}$ The second involves detection of cognition impairment, even if it is mild. It does not mean that the patient cannot decide for him/herself, 


\section{Figure 1}

Proposed algorithm to evaluate older patients with chronic kidney disease (adapted from ERA-EDTA - 2).

REGULAR ASSESSMENT FOR PATIENTS WITH AGE> AND CONFIRMED EGFR BETWEEN 15 AND 45ML/MIN

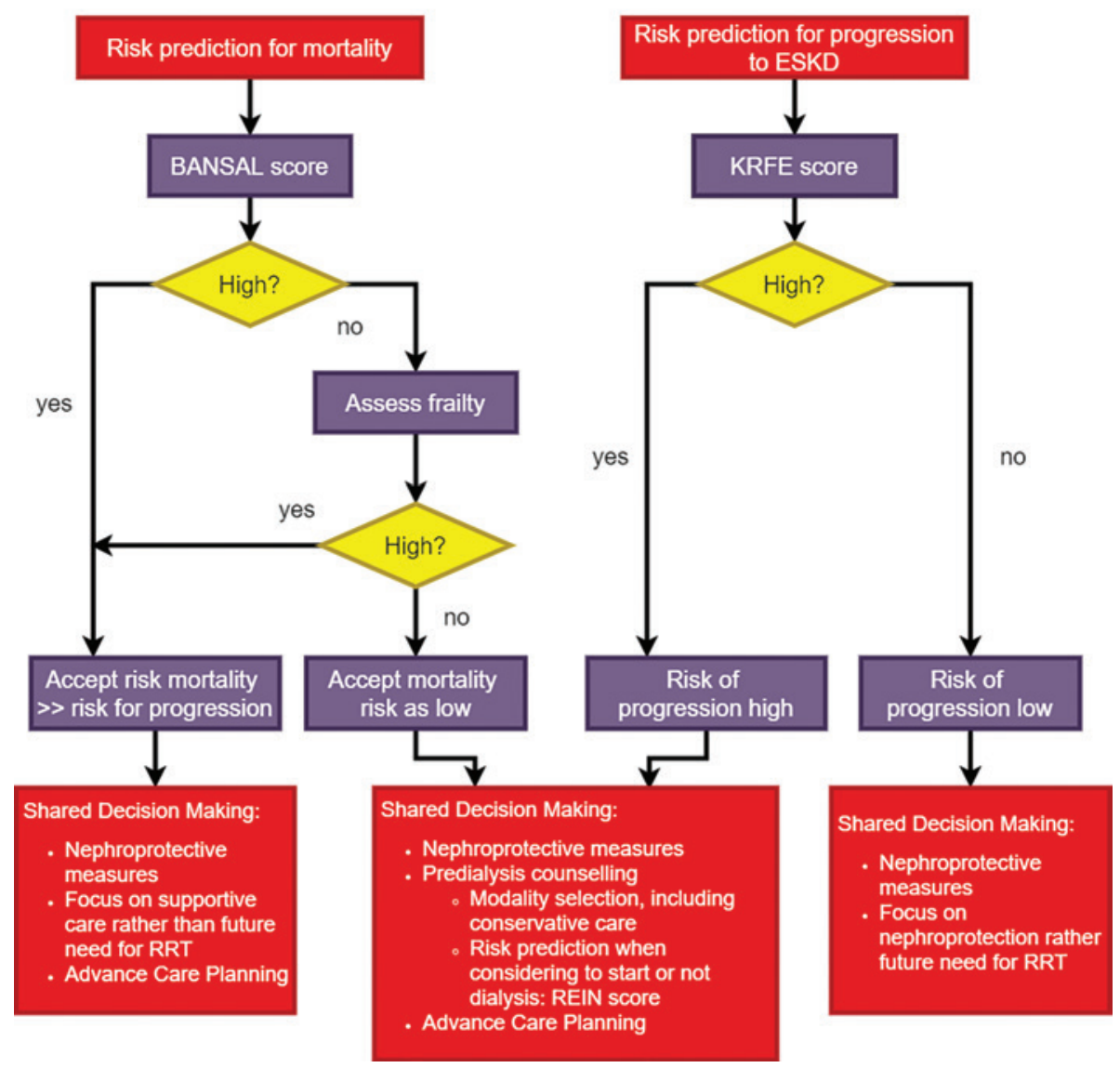

but diagnosis may potentiate rehabilitation of limitations that may disturb the decision. Syndromes that affect independence, such as visual or hearing impairment, (Figure 2) may condition this choice. The best way to detect these changes is by applying Comprehensive Geriatric Assessment tools. ${ }^{6}$ As used in oncology, it would allow to evaluate, to rehabilitate and to assess the likelihood of tolerating aggressive treatments like hemodialysis (HD) in frail patients. On the other hand, it should not exclude fit patients from transplantation, which still provides the best survival option in healthy aged patients (Table 1). This evaluation may also identify hidden causes of deterioration other than uremic syndrome. Elderly patients tend to initiate dialysis at a higher glomerular filtration rate based on subjective symptoms (e.g. fatigue, nausea, etc.) that may not be caused by ESKD and that wouldn't improve with dialysis or may even worsen. ${ }^{7}$ That powerful confounder may contribute to the high rates of mortality in the first 3 months after the beginning of dialysis. Improving and rehabilitating geriatric syndromes may have a greater impact on mortality rate than the KRT modality itself. ${ }^{8}$
The importance of diagnosing geriatric syndromes to provide better elderly care is recognized by several societies such as KDIGO (which advocates that frailty should be assessed) $)^{9}$ or ERA-EDTA ERBP, which dedicated an entire guideline to review the management of older CKD patients from stage $3 b^{2}$.

In terms ofcommunication, nephrologists are privileged because they tend to follow the patient for a long time. It allows us to meet the patient before they lose the ability to decide or when they do, to have lengthy prior discussions and then to choose a KRT consistent with patient goals, without compromising quality of life. This requires understanding the patient's priorities, values, and preferences about medical care, even if their preferences are not what their family members (or physicians) would wish. However, it is important to remember that the patient may change his or her mind at subsequent visits, and nephrologists should access options and goals during multiple visits over time, regardless of the patient's initial choice. $^{10}$ 


\section{Figure 2}

Geriatric Syndromes (in blue squares) that impair independence and autonomy to make options.
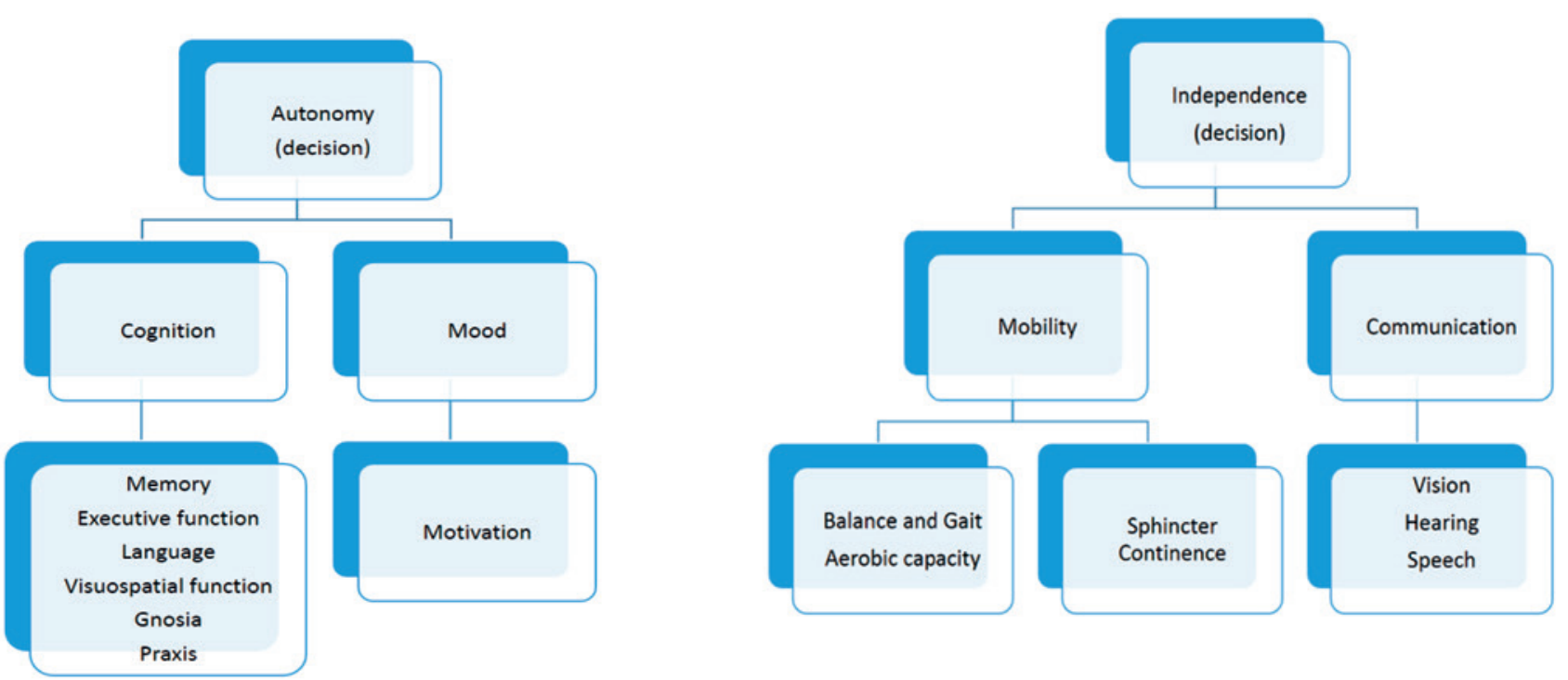

\section{Cognitive impairment}

Postural instability

\section{Table 1}

Function age, its evaluation and recommendations for KRT.

\begin{tabular}{|c|c|c|c|}
\hline Functional Age & & Clinical Description & Recommendations for KRT \\
\hline $\begin{array}{l}\text { Healthy/usual } \\
\text { or fit }\end{array}$ & $\begin{array}{l}\text { - Few hospitalizations; } \\
\text { - Good QoL. }\end{array}$ & $\begin{array}{l}\text { - KPS > 80; } \\
\text { - Independent in ADLs and IADLs } \\
\text { - Low comorbidity score (CCI <4) } \\
\text { - No geriatric syndromes (dementia, frailty, functional disabili- } \\
\text { ty, depression, malnutrition, falls); } \\
\text { - Negative physical frailty testing; } \\
\text { - Answer yes to surprise question. }\end{array}$ & - Optimal for dialysis or transplant. \\
\hline $\begin{array}{l}\text { Vulnerable or } \\
\text { intermediate }\end{array}$ & - Increasing hospitalizations. & $\begin{array}{l}\text { - KPS 50-80; } \\
\text { - Dependent in one ADL and iADLs. } \\
\text { - Comorbidity score (CCI 5-7), REIN clinical score <9; } \\
\text { - 1-2 geriatric syndromes; } \\
\text { - Prefrail (1-2 criteria) to } 1 \text { frailty testing; } \\
\text { - Unclear answer to surprise question: I don't know. }\end{array}$ & $\begin{array}{l}\text { - Typical dialysis patient; } \\
\text { - Assessment of and intervention on geriatric issues to opti- } \\
\text { mize factors that may adversely affect outcomes. }\end{array}$ \\
\hline Frail & $\begin{array}{l}\text { - Susceptible to poor out- } \\
\text { comes; } \\
\text { - High risk of hospitalizations; } \\
\text { - Nursing home patients with } \\
\text { notable disability. }\end{array}$ & $\begin{array}{l}\text { - KPS <50; } \\
\text { - Dependent in >2 ADLs and iADLS; } \\
\text { - Significant symptom burden; } \\
\text { - Answer no to the surprise question; } \\
\text { - High comorbidity score (CCI 8), REIN score 9; } \\
\text { - >2 geriatric syndromes; } \\
\text { - Physical frailty; } \\
\text { - Cognitive dysfunction; } \\
\text { - Inability to transfer. }\end{array}$ & $\begin{array}{l}\text { - Suboptimal dialysis candidate; } \\
\text { - Recommend NDMT or time-limited trial of dialysis. }\end{array}$ \\
\hline
\end{tabular}




\section{TREATMENT OPTIONS}

First of all, this paper does not intend to teach ESKD treatment modalities, but instead to reflect on the particularities of aged patients.

The second point crucial to stress is that we are not discussing timing of initiation, which is beyond the scope of this paper. ${ }^{6}$

Third, there are no randomized controlled trials that compare the different modalities. That would be completely unethical. So extrapolations to individual patients may always seem abusive.

Finally, the most important consideration is function, not age. This is primordial to avoid the decline associated with iatrogenesis, either by omission or by addition. In Portugal, in this population, the benefits of transplantation are underestimated, but the profits of dialysis are overestimated. The balance should be somewhere in the middle.

\section{Kidney transplantation}

Kidney transplantation (KT) improves the long-term survival and quality of life of most patients with ESKD, including the older ones. However, in this specific population, KT benefits are only realized 1.5 to 2 years after transplantation. ${ }^{11}$ Elderly patients with significant comorbidities may not live long enough to realize those benefits, because they are more susceptible to geriatric syndromes, immunosuppression-related complications and chronic graft failure. This vulnerability could lead to prolonged recovery, decrease of functional capacity, and increase risk of hospitalization and complications. When elderly kidney recipients are considering transplantation, perception of prognosis, goals and the vulnerability of age should be discussed. ${ }^{12}$

\section{Pre-transplant evaluation}

Besides the usual evaluation, a careful assessment of older candidates is essential to avoid an invasive procedure in patients who will not benefit, and to avoid wasting a kidney. A baseline cognitive and physical function evaluation should be performed, as well as exclusion of geriatric syndromes. Significant deficits increase the risk of poor outcomes, including all-cause graft loss. Also, provision of strong social support should be required before and after transplantation. Anyway, it continues to be the number one option for fit patients

Several screening tools have emerged to help identify suitable kidney transplant candidates. A risk score of mortality within 3 years was elaborated through data from the French national registry (REIN score - Table 2). ${ }^{13}$ A score of 0 to 6 points corresponds to a $70 \%$ probability of being alive within 3 years. A similar screening tool is the Physical Function (PF), through Short Form-36 questionnaire. A study that combined data of pre-transplant and UNOS registry data detected a 3-year mortality difference across PF quartiles in all age strata above 35 years old. ${ }^{14}$ The Physical Frailty Phenotype has also emerged as a screening tool for poor prognosis, being useful to identify vulnerable patients who do not have otherwise apparent disability or comorbidity. The frailty status should be evaluated at pre-transplantation and monitored while on the waitlist. ${ }^{11}$

\section{Table 2}

REIN score.

\begin{tabular}{l||c}
\multicolumn{1}{c|}{ Variables } & Points \\
\hline Male & 1 \\
Age $75-80$ years old & 2 \\
\hline Age 80 to 85 years & 5 \\
Age $>85$ years & 9 \\
Diabetes & 2 \\
\hline Intermittent hemodialysis & 2 \\
\hline Peripheral vascular disease, stage III to IV & 5 \\
\hline Congestive heart failure, stage I to II & 2 \\
\hline Congestive heart failure, stage III to IV & 4 \\
\hline Arrhythmia & 2 \\
\hline Chronic respiratory disease & 2 \\
\hline Active malignancy & 5 \\
\hline Severe behavioral disorder & 6 \\
Cardiovascular disease & 1 \\
\hline Decreased mobility (needs assistance for transfers) & 4 \\
\hline Totally dependent & 9 \\
\hline Body mass index 21 to 25 & 1 \\
\hline Body mass index $<21$ to 25 & 3 \\
Central venous catheter & 3 \\
\hline Adapted from ${ }^{13}$. & \\
\hline
\end{tabular}

Independent of age, all candidates should undergo routine cancer screening, in accordance with with local guidelines for the general population, with specificities in some situations:

- Candidates at increased risk for renal cell carcinoma, bladder carcinoma and hepatocellular carcinoma should be screened;

- Smoker candidates should be screened for occult lung cancer, with chest computed tomography for current or former heavy tobacco users ( $\geq 30$ pack-years), and chest X-ray for other candidates.

Also, the timing for KT after potentially curative treatment for cancer depends on the cancer type and stage at diagnosis. With indolent and low-grade cancers, in remission after potentially curative therapy, the candidate could be considered for KT: prostate cancer (Gleason score $\leq 6)$, superficial non-melanoma skin cancer and incidentally detected renal tumors $\left(\leq 1 \mathrm{~cm}\right.$ in maximum diameter). ${ }^{15}$

\section{Immunosuppressive therapy}

Immunosuppression in the elderly can be a challenge, because this population presents pharmacokinetics and pharmacodynamics changes, polypharmacy and decrease immunocompetence (immunosenescence), with the need for adjustment of standard protocols. ${ }^{12}$ The pharmacokinetics of drugs, particularly calcineurin inhibitors, may be altered in older adults. A decline in cytochrome P450 activity leads to a need for lower doses of calcineurin inhibitors. In addition, intracellular mechanisms essential to drug efficacy could be compromised. ${ }^{11}$

On the other hand, the risk for acute rejection is lower in the elderly population, because of immunosenescence. Nevertheless, it 


\section{$\underline{\text { Table } 3}$}

Suggested guidelines for cancer screening in patients undergoing solid organ transplantation.

\begin{tabular}{|c|c|}
\hline Cancer & Recommendation \\
\hline Breast & $\begin{array}{l}\text { - Women } 50 \text { to } 69 \text { years: annual screening mammography with or without clinical breast examination; } \\
\text { - } 40 \text { to } 49 \text { years: the benefit of screening is less certain and should be left to the decision of the clinician and patient; } \\
\text { - } \geq 70 \text { years of age: annual screening is appropriate as long as estimated life expectancy is } \geq 8 \text { years. }\end{array}$ \\
\hline Skin & $\begin{array}{l}\text { - Monthly self-examination; } \\
\text { - Clinician examination annually, with early referral for suspected lesions. }\end{array}$ \\
\hline Cervical & - All women $\geq 18$ years old and sexually active girls <18 years old: annual pelvic examination and Pap smear. \\
\hline Anogenital & $\begin{array}{l}\text { - Yearly physical examination of the anogenital area, including pelvic examination and cytologic studies for women. Insufficient evidence to rec- } \\
\text { ommend for or against screening anoscopy and biopsies of anal epithelium. }\end{array}$ \\
\hline Kaposi sarcoma/other sarcomas & $\begin{array}{l}\text { - Examination of skin, conjunctivae, and oropharyngeal mucosa annually; } \\
\text { - Patients at higher risk (ethnicity, geographic area of residence or serologic positivity for HHV-8) may benefit from more frequent screening. }\end{array}$ \\
\hline Prostate & $\begin{array}{l}\text { - Men } \geq 50 \text { years: annual screening with digital rectal examination and PSA, if their estimated life expectancy is at least } 10 \text { years; } \\
\text { - If positive family history or African-American race, may start annual screening earlier. }\end{array}$ \\
\hline Colorectal & - $\geq 50$ years: annual fecal occult blood testing and either sigmoidoscopy every five years or colonoscopy every 10 years. \\
\hline PTLD & - Complete history and physical examination every three months, particularly in the first posttransplant year. \\
\hline Hepatocellular cancer & - For patients with chronic hepatitis B or C and cirrhosis, serum AFP alpha-fetoprotein and liver ultrasound every 6 to 12 months. \\
\hline Renal cell & - Not recommended, except possibly for patients with a history of analgesic abuse. \\
\hline Lung & - Not recommended. \\
\hline
\end{tabular}

Abbreviations: PSA: prostate specific antigen; HHV-8: human herpesvirus 8; PTLD: posttransplant lymphoproliferative disorder.

can also imply a higher susceptibility to infections, leading to higher rates of hospitalization and graft loss. Still, the elderly tend to receive kidneys from expanded criteria and older donors, which are associated to higher rates of acute complications and early graft failure. ${ }^{11,16}$

Due to the theoretically lower risk of acute rejection, some centers do not administer induction therapy with antibodies to older recipients, even if retrospective data suggest a better outcome with induction therapy. However, induction therapy may allow a maintenance therapy without antimetabolites. ${ }^{11}$

Therefore, the best regimen for elderly patients is unknown. Ideally, immunosuppressive therapy in transplantation should be personalized, especially in this population.

\section{Long-term complications}

Infections are some of the most worrisome complications in transplanted patients. The same happens in the elderly: infections are more common in the first 6 months, a consequence of induction immunosuppressive therapy. They correlate with the degree of immunosuppression independent of age. In the elderly, immunosenescence leads to a higher rate of and more severe infections at lower levels of immunosuppression. Mortality rate related to infections increases exponentially in transplant recipients with increasing age, and is the first cause of death in the elderly. ${ }^{16}$

Cancer is the third cause of death after KT. The incidence of most cancers increase with age, probably due to immunosenescence, increased the susceptibility of aging tissues to carcinogens and time required for carcinogenesis. Immunosuppressive therapy also increases the incidence of cancer 2 to 20 times when compared with age-matched controls. ${ }^{16}$ For the post-KT period, the American Society of Transplantation has published guidelines for cancer screening (Table 3). ${ }^{17}$
In conclusion, a pre-KT study and close surveillance are essential in the setting of immunosuppressive therapy, particularly in the elderly.

\section{Graft survival}

Independent of age, graft survival is higher for living-donor transplants, and is the ideal transplantation option. In deceased-donor transplants, older recipients tend to receive a kidney from older donors ("old-for-old" allocation strategy), when they are not passed over or excluded in favor of younger patients (the ethics of this situation is outside the scope of this review). However, most of the graft loss in elderly transplant patients occurs with patient death. As mentioned earlier, acute rejection is not common, but there is an increased risk of chronic rejection that increases with donor age. A North American retrospective study showed that increasing recipient age is associated with an improved transplant survival, lower rates of rejection and superior outcome of older donor organs. ${ }^{18,19}$

Living donation from older donors should also be explored to expand the opportunity of receiving a transplant. ${ }^{18}$ Aged donors should be clinically evaluated also by a geriatric team, featuring a comprehensive geriatric assessment methodology.

\section{- Hemodialysis}

Elderly patients are a growing group in the HD population. Geriatric patients present a significantly higher mortality risk when compared with other chronic illness, such as cancer, cardiovascular disease and diabetes. ${ }^{20,21}$ In 2018, the HD gross mortality rate in Portugal was $13.78 \%$ (1660 patients), of which $82.1 \%$ were over 65 years old and $44.2 \%$ over 80 years. ${ }^{22}$

It is interesting to realize that in the United States, HD patients present higher rates of hospitalization (76\%) and intensive care unit 
admissions (49\%) during the final month of life than cancer and heart failure patients. ${ }^{20}$ Several risk factors have been associated to poor outcomes in HD patients, namely increasing age, hypoalbuminemia $(<2.5 \mathrm{~g} / \mathrm{dL})$, low body mass index $(<20)$ and geriatric syndromes. The causes of higher prevalence of those syndromes in HD elderly population are not well established, but uremia, KRT complications, demands of routine HD and comorbidities probably have a significant impact. For example, hypotension occurrence is more frequent in older patients, even if weight gain is less than in younger patients. This contributes to an increase in falls and immobility as well as cognitive decline. These factors are also responsible for a higher prevalence of debilitating physical and emotional symptoms. 23

Even if HD is mostly seen as a life-sustaining therapy, the patient trajectory is widely recognized with a slower or faster progressive decline that can be accelerated by several variables. Acute complications are examples that bring more burden in elderly patients and their caregivers. Nevertheless, even HD schedules, which involve travel to and from dialysis, or the stress of achieving standard performance goals, such as the creation of an arteriovenous fistula (AVF) or a target dialysis efficiency, may contribute to worse quality of life. ${ }^{20,21}$ Incremental HD presents as a more individualized approach to selected patients, for whom the main goal is quality of life. This allows shorter or less frequent treatments, particularly in those who still have residual kidney function. Minimizing uremic symptoms is a priority, but without imposing adequacy targets. Ultimately, in patients with low life expectancy, HD burdens may outweigh its benefits and a palliative approach may be more desirable. This may occur in patients who were stable in HD for a period but in whom a change in condition may make HD no longer worthwhile. Recognition of those patients could allow us to minimize the physical and psychological burdens of this technique. ${ }^{20}$ This means that even when the patient has made an initial KRT choice and has been stable, modality choices must be assessed for the patient's wellbeing.

\section{Vascular access}

The optimal type of initial vascular access among the elderly is controversial, although actual guidelines strongly recommend placement of an AVF in preference to an arteriovenous graft (AVG).

AVF non-maturation is higher in elderly patients, something which is strongly influenced by several comorbidities, such as diabetes and coronary or peripheral artery diseases. In addition, older patients might not live long enough to see the benefits of AVF on survival. When compared to AVF, AVG maturation is usually faster. Furthermore, there is the alternative of an early cannulation graft. On the other hand, central vascular catheter (CVC) dependence is generally associated with a higher complication rate (e.g. bacteremia, hospitalizations), and mortality. Older patients submitted to AVF placement are exposed to longer permanence of CVC and to its complications. However, a study of 2017 showed that despite the longer CVC dependence, the AVF elderly had a lower frequency of hospitalizations related to all-cause infection and septicemia and a lower risk of death. ${ }^{24}$ Two other works revealed that, among patients starting HD with a CVC, those who underwent AVF placement before HD initiation had superior survival when compared to those without pre-dialysis access placement, despite the similar comorbidities' profile. Time of CVC dependence did not interfere with survival, because higher survival was evident even when AVF had primary failure. ${ }^{25,26}$

In terms of AVF location, proximal fistulas may be preferred because old patients may not live long enough to exhaust vascular options. ${ }^{27}$

That suggests that vascular access placement in the elderly should be an individualized choice, considering patient comorbidities and life expectancy.

\section{Peritoneal Dialysis}

In Portugal, as in most industrialized countries, a minority of patients choose peritoneal dialysis (PD). In 2018 , only $8.7 \%$ of patients started on PD in Portugal, as in previous years. ${ }^{22}$ In a Dutch study, older age was associated with significant contraindications for PD. In line with nephrologists' opinions, the most frequent contraindication was the expected inability to perform exchanges by themselves and $97 \%$ of social contraindications were for PD. ${ }^{28}$ Thus, PD choice is often set aside because of the burden on family and caregivers. Psychosocial and physical barriers could be overcome if we provide proper support. Assisted PD could be an alternative, allowing patients to maintain treatment at home. ${ }^{29,30}$ Nowadays, assisted PD is evolving in several regions, but France presents the greater experience. Around half of PD patients need support, mainly obtained through a private nurse. PD assisted by a caregiver is also an alternative in some situations yet increases the burden and stress on family. ${ }^{29,31}$

From a palliative perspective, PD could reach patient preferences and goals of care, and this should not be ignored. PD type (continuous versus intermittent) and the intensity (duration, number of exchanges, fill volumes, etc.) should be adjusted to maximize quality of life, while minimizing uremic symptoms. Once more, in these patients, technique survival becomes more important than adequacy targets. When compared with HD, incremental dialysis could be easier to implement because of logistic factors (schedules at outpatient dialysis facilities). ${ }^{29}$

PD is not an innocuous technique, with peritonitis remaining as one of the most important complications, even if infections rates are similar to those seen in younger cohorts. Moreover, wound healing capability, especially important after catheter placement, could be impaired in malnourished and diabetic elderly patients. PD pros and cons should also be discussed with the patient and family (when necessary), considering patient goals of care and life expectancy. For this purpose, it is important that health systems urgently find a solution that allows elderly patients an actual choice, ideally without a complete dependence on caregivers. ${ }^{31}$

Concerns over altered physiology related to aging (such as constipation or increased incidence of diverticulitis) should not be a limitation. Equally so, nutritional issues should be not seen as a contraindication to the technique, since there are not enough studies to show otherwise. 


\section{Table 4}

Pros and cons of each modality of treatment of ESKD in elderly.

\begin{tabular}{|c|c|c|}
\hline Modality & Pros & Cons \\
\hline Kidney transplantation & - Maximum life expectancy and quality of life, if applicable. & - Limited to fit patients, because of associated risks. \\
\hline Hemodialysis & - Do not depend on a caregiver, but in an institution (if in-center dialysis). & $\begin{array}{l}\text { - Vascular access placement and its complications; } \\
\text { - Increased risk of complications, including hemodynamic instability, and } \\
\text { cognitive decline. }\end{array}$ \\
\hline Peritoneal Dialysis & $\begin{array}{l}\text { - In home-based KRT; } \\
\text { - Preserve residual renal function for longer period. }\end{array}$ & $\begin{array}{l}\text { - Catheter placement; } \\
\text { - Depend on a caregiver, if assisted PD; } \\
\text { - Relative contraindication more frequent (previous abdominal surgery, } \\
\text { bowel disease, colostomy). }\end{array}$ \\
\hline Conservative Care & - Focused on patients' goals of care and quality of life. & - Do not substitute kidney function. \\
\hline
\end{tabular}

\section{- Conservative Care and Palliative Care}

For frail patients who may not benefit from more aggressive therapies, principles from palliative medicine have been brought to care for CKD patients. In parallel with what happens in oncology, patients who are no longer candidates for invasive therapies have the right to be cared for as well. This approach, without KRT, has been called Conservative Care (CC), ${ }^{32}$ an inaccurate term that should not be confused with the measures taken to delay the progression of kidney disease, to prevent complications associated with it and to conserve residual kidney function. It should also not be confused with end-of-life care. Indeed, it is a mix of all these measures to assess patient needs and not disease-focused procedures. Implications of this option should be clarified in an advance care plan and regarding the main ethical principles of medicine: beneficence, non-maleficence, justice and last but not least, autonomy. That last one brings us to another pillar of palliative medicine: communication - the base of shared decisions. Patients who decide not to proceed to KRT, whose life expectancy is less than one year or even patients stable on KRT but who have a change in their condition, may opt for CC. Realistic information on prognosis, expected quality of life and symptom control in each CKD modality approach should be presented. Dialysis should not be seen as an inevitability or imposition, but as a free choice. These discussions should not be avoided because of reluctance to approach them, lack of confidence in predicting prognosis, fear of abolishing hope or discomfort. The major concern in CC is symptom control and quality of life of patient and family. ${ }^{23,33}$

Even if theoretically desirable according to Portuguese guidelines, $\mathrm{CC}$ is not widely available. ${ }^{34}$ As long as it is not an option for everyone who needs it, options to take care of ESKD patients are limited.

\section{CONCLUSION}

Choosing the best treatment option for ESKD elderly patients is hard for both doctors and patients. Every time that we face a lifelong decision, we must carefully evaluate pros and cons (Table 4). Costs should not influence the choice. Absence of family support should not also limit decisions. Individualize the option is the most humanized form of doing it. Turning the option into a more reproducible and scientific one is best practice in medicine. Thus, evaluating an aged person as a whole and not limiting options based on chronologic age

\section{Table 5}

Approach to decision making in elderly patients with CKD.

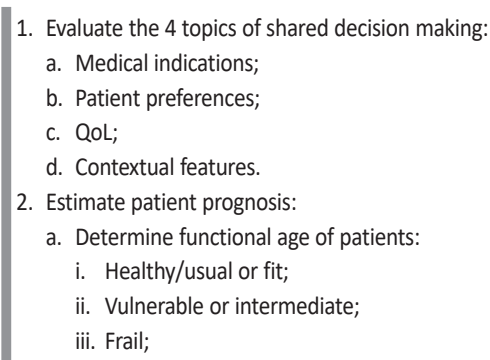

b. Use disease trajectories to predict clinical course.

3. Discuss recommendations with patients and families:

a. Develop a treatment plan based on the aforementioned factors in a shared decision with patients and families;

b. If disagreement exists, or prognosis is unclear, offer a time-limited trial of dialysis with predefined targets.

4. Integrate a geriatric renal palliative care approach at CKD stage 4 to:

a. Continue predialysis care: treatment of anemia, mineral bone disease, volume status, hypertension, hyperlipidemia, and electrolyte abnormalities;

b. Discuss ACP:

i. To aid in communication with patients and caregivers;

ii. To decrease burdens and strengthen relationships;

iii. To name an HCP.

iv. Specify wishes for the end of life;

c. Control symptoms;

d. Assess and treat geriatric syndromes;

e. Provide practical, psychosocial, and spiritual care to patients and families/caregivers. Abbreviations: ACP, advanced care planning; ADL, activities of daily living; $\mathrm{CCl}$, Charlson Comorbidity Index (see text); CKD, chronic kidney disease; ESKD, end stage kidney disease; HCP, heath care proxy; iADL, instrumental activities of daily living; KPS, Karnofsky Performance Scale; KRT, kidney replacement therapy; PD, peritoneal dialysis; QoL, quality of life; REIN score, Renal Epidemiology and Information Network Prognosis score (see text). Physical frailty ( 5 means 3 or more of the following criteria: unintentional weight loss of more than $10 \mathrm{lb}$ in last year, self-reported exhaustion, weakness (grip strength), slow walking speed, low physical activity. Karnofsky Performance Score: 100: normal, no complaints, no evidence of disease; 80 : normal activity with effort, some symptoms or signs of disease; 50: requires considerable assistance and frequent medical care.

is an imperative (Table 5). But ultimately, we still wouldn't have magical crystal balls, so we limit ourselves to hoping for the best and preparing for the worst, always supporting our patient.

Disclosure of potential conflicts of interest: none declared 


\section{References}

1. Freidin N, O'Hare AM, Wong SPY. Person-centered care for older adults with kidney disease: core curriculum 2019. Am J Kidney Dis 2019;74(3):407-416

2. Farrington K, Covic A, Aucella F, et al. Clinical practice guideline on management of older patients with chronic kidney disease stage $3 \mathrm{~b}$ or higher (eGFR $<45 \mathrm{~mL} / \mathrm{min} / 1.73 \mathrm{~m} 2$ ). Nephrol Dial Transplant 2016;31(2):ii1-ii66.

3. Tangri N, Stevens LA, Griffith J, et al. A predictive model for progression of chronic kidney disease to kidney failure. JAMA 2011;305(15):1553-1559.

4. Bansal N, Katz R, De Boer IH, et al. Development and validation of a model to predict 5-year risk of death without ESRD among older adults with CKD. Clin J Am Soc Nephrol 2015;10(3):363-371.

5. Farinha A. Prognostication in end-stage renal disease. Port J Nephrol Hypert 2016;30(4):299-304.

6. Farinha A, Duque S. Comprehensive geriatric assessment in nephrology. Port J Nephrol Hypert 2019;33(3):168-175

7. Rivas Velasquez KM, Hames E, Masri H. Evaluation and management of the older adult with chronic kidney disease. Prim Care 2014;41(4):857-874.

8. Hall RK, Haines C, Gorbatkin SM, et al. Incorporating geriatric assessment into a nephrology clinic: preliminary data from two models of care. J Am Geriatr Soc 2016;64(10):2154-2158.

9. Chan CT, Blankestijn PJ, Dember LM, et al. Dialysis initiation, modality choice, access, and prescription: conclusions from a Kidney Disease: Improving Global Outcomes (KDIGO) Controversies Conference. Kidney Int 2019;96(1):37-47.

10. Davison SN. End-of-life care preferences and needs: perceptions of patients with chronic kidney disease. Clin J Am Soc Nephrol 2010;5(2):195-204.

11. Brennan DC, DeMarco MM. Kidney transplantation in adults: kidney transplantation and the older adult patient. Post TW, ed. UpToDate. Waltham, MA: UpToDate Inc: (Accessed June, 2020).

12. Pinter J, Hanson CS, Chapman JR, et al. Perspectives of older kidney transplant recipients on kidney transplantation. Clin J Am Soc Nephrol 2017;12(3):443-453.

13. Dusseux E, Albano L, Fafin C, et al. A simple clinical tool to inform the decision-making process to refer elderly incident dialysis patients for kidney transplant evaluation. Kidney Int 2015;88(1):121-129.

14. Reese PP, Bloom RD, Shults J, et al. Functional status and survival after kidney transplantation. Transplantation 2014;97(2):189-195.

15. Chadban SJ, Ahn C, Axelrod DA, et al. Summary of the Kidney Disease: Improving Global Outcomes (KDIGO) Clinical Practice Guideline on the Evaluation and Management of Candidates for Kidney Transplantation. Transplantation 2020;104(4):708-714. doi: 10.1097/TP.0000000000003137 [published Online First: 2020/04/01]

16. Martins PN, Pratschke J, Pascher A, et al. Age and immune response in organ transplantation. Transplantation 2005;79(2):127-132.

17. Acuna SA, Huang JW, Scott AL, et al. Cancer screening recommendations for solid organ transplant recipients: a systematic review of clinical practice guidelines. Am J Transplant 2017;17(1):103-114. doi: 10.1111/ajt.13978 [published Online First: 2016/08/31]

18. Tso PL, Dar WA, Henry ML. With respect to elderly patients: finding kidneys in the context of new allocation concepts. Am J Transplant 2012;12(5):1091-1098.
19. Tullius SG, Tran H, Guleria I, et al. The combination of donor and recipient age is critical in determining host immunoresponsiveness and renal transplant outcome. Ann Surg 2010;252(4):662-674.

20. Grubbs V, Moss AH, Cohen LM, et al. A palliative approach to dialysis care: a patient-centered transition to the end of life. Clin J Am Soc Nephrol 2014;9(12):2203-2209.

21. Swidler MA. Geriatric renal palliative care. J Gerontol A Biol Sci Med Sci 2012;67(12):1400-1409.

22. Portuguese Registry of Dialysis and Transplantation. Portuguese Society of Nephrology, 2018.

23. Malavade T, Sokwala A, Jassal SV. Dialysis therapies in older patients with end-stage renal disease. Clin Geriatr Med 2013;29(3):625-639.

24. Lee $\mathrm{T}$, Thamer $\mathrm{M}$, Zhang $\mathrm{Q}$, et al. Vascular access type and clinical outcomes among elderly patients on hemodialysis. Clin J Am Soc Nephrol 2017;12(11):1823-1830.

25. Brown RS, Patibandla BK, Goldfarb-Rumyantzev AS. The survival benefit of "fistula first, catheter last" in hemodialysis is primarily due to patient factors. J Am Soc Nephrol 2017;28(2):645-652.

26. Quinn RR, Oliver MJ, Devoe $D$, et al. The effect of predialysis fistula attempt on risk of all-cause and access-related death. J Am Soc Nephrol 2017;28(2):613-620.

27. Wright S, Danziger J. Vascular Access for Hemodialysis in the Elderly. In: ASN, ed. Online Curricula: Geriatric Nephrology, 2009.

28. Jager KJ, Korevaar JC, Dekker FW, et al. The effect of contraindications and patient preference on dialysis modality selection in ESRD patients in The Netherlands. Am J Kidney Dis 2004;43(5):891899.

29. Povlsen JV, Ivarsen P. Assisted peritoneal dialysis. Adv Chronic Kidney Dis 2007;14(3):279-283.

30. Sakai K, Nihei H. Peritoneal dialysis in elderly patients. Contrib Nephrol 2018;196:141-147.

31. Verger C, Duman M, Durand PY, et al. Influence of autonomy and type of home assistance on the prevention of peritonitis in assisted automated peritoneal dialysis patients. An analysis of data from the French Language Peritoneal Dialysis Registry. Nephrol Dial Transplant 2007;22(4):12181223.

32. DGS. Norma 017/2011 - Tratamento Conservador Médico da Insuficiência Renal Crónica Estádio 5, 2011.

33. Crail S, Walker R, Brown M, et al. Renal supportive and palliative care: position statement. Nephrology (Carlton) 2013;18(6):393-400.

34. Farinha A, Branco A. Seven years after "Norma 17": what has changed? Port J Nephrol Hypert 2018 2018;32(1):93-97.

\section{Correspondence to:}

Patrícia Valério, MD

Hospital de São Bernardo - Serviço de Nefrologia, Rua Camilo Castelo Branco 175, 2910-446 Setúbal

E-mail: p.valerios89@gmail.com 